\title{
ATM and ATR signaling at a glance
}

\section{Poorwa Awasthi ${ }^{1,2}$, Marco Foiani ${ }^{3,4, *}$ and Amit Kumar ${ }^{1,2, *}$}

\section{ABSTRACT}

ATM and ATR signaling pathways are well conserved throughout evolution and are central to the maintenance of genome integrity. Although the role of both ATM and ATR in DNA repair, cell cycle regulation and apoptosis have been well studied, both still remain in the focus of current research activities owing to their role in cancer. Recent advances in the field suggest that these proteins have an additional function in maintaining cellular homeostasis under both

\footnotetext{
${ }^{1}$ Developmental Toxicology Laboratory, Systems Toxicology and Health Risk Assessment Group, CSIR-Indian Institute of Toxicology Research, M.G. Marg 80 Lucknow 226001, India. ${ }^{2}$ Academy of Scientific and Innovative Research (AcSIR), CSIR-IITR campus, Lucknow 226001, India. ${ }^{3}$ IFOM (Fondazione Istituto FIRC di Oncologia Molecolare), IFOM-IEO Campus Via Adamello 16, Milan 20139, Italy.

${ }^{4}$ DSBB-Università degli Studi di Milano, Milan 20133, Italy.

stressed and non-stressed conditions. In this Cell Science at a Glance article and the accompanying poster, we present an overview of recent advances in ATR and ATM research with emphasis on that into the modes of ATM and ATR activation, the different signaling pathways they participate in - including those that do not involve DNA damage - and highlight their relevance in cancer.

\section{KEY WORDS: ATM, ATR, Cell cycle, DNA damage, Genome integrity}

\section{Introduction}

Ataxia-telangiectasia-mutated (ATM) and ataxia telangiectasia and Rad3-related (ATR) proteins are key regulators of the DNA damage response (DDR), and maintain genome integrity in eukaryotic cells. ATM and ATR are expressed in most tissues, and mutations in the encoding genes result in the autosomal recessive disorders ataxia telangiectasia (Lavin, 2008) and Seckel syndrome (O’Driscoll et al.,

\section{Cell Science \\ ATM and ATR Signaling at a Glance} \section{Poorwa Awasthi, Marco Foiani and Amit Kumar}

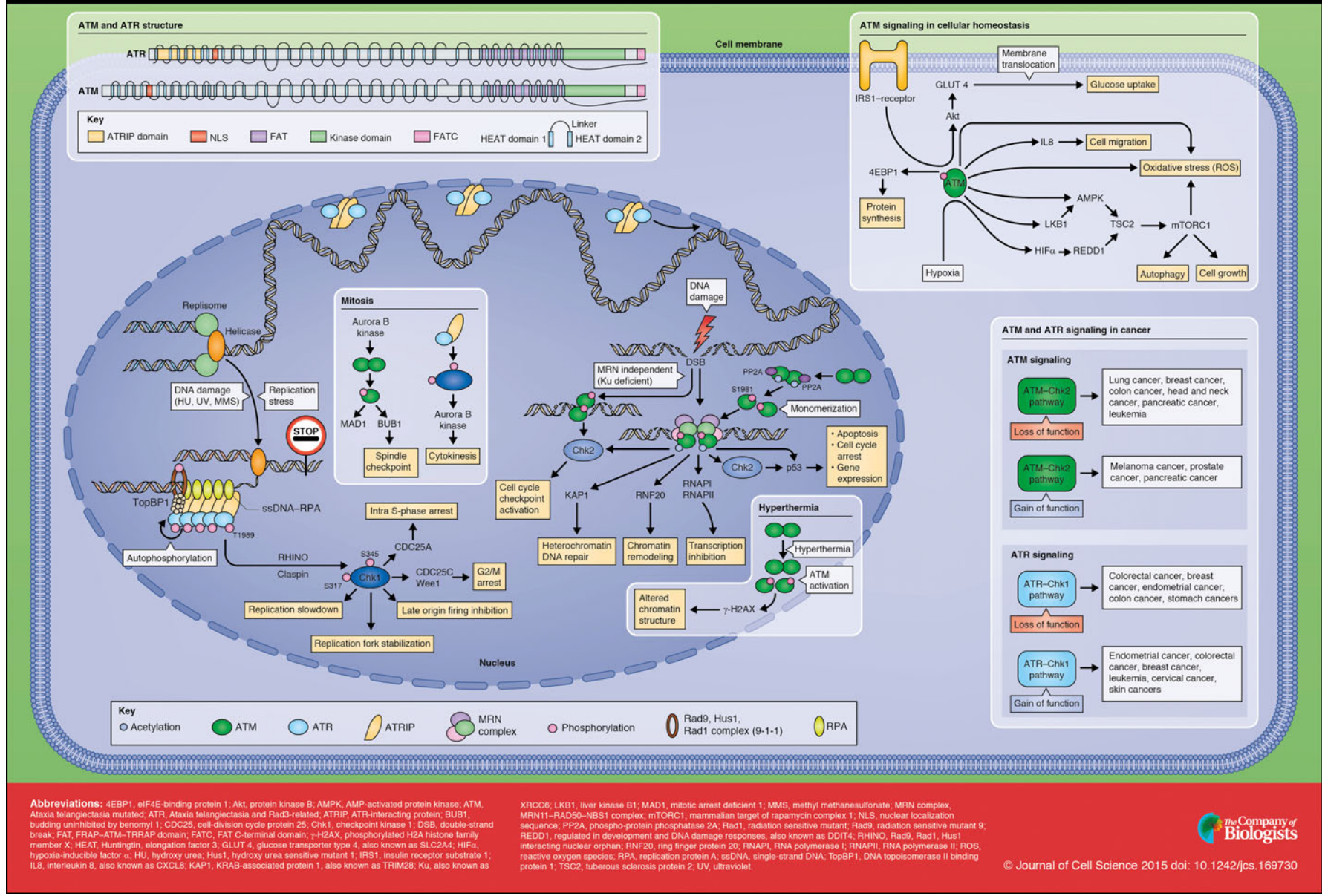


2003), respectively. The clinical manifestations of ataxia telangiectasia include progressive ataxia, telangiectasia, immune defects, genome instability and malignancy; Seckel syndrome is characterized by postnatal dwarfism, microcephaly, intrauterine growth defects and mental retardation. Savitsky and co-workers first described $A T M$ as the gene responsible for ataxia telangiectasia (Savitsky et al., 1995), whereas ATR was first identified and cloned from human T cells (Cimprich et al., 1996). ATM and ATR belong to the class-IV phosphoinositide 3-kinase (PI3K)-related kinase (PIKK) family, along with mammalian target of rapamycin (mTOR) and DNA-dependent protein kinase (DNA-PK). ATM and ATR nonetheless lack lipid kinase activity; instead, they phosphorylate proteins that contain Ser or Thr residues that are followed by Gln (SQ or TQ motifs) (Bakkenist and Kastan, 2004). DDR is mediated by ATM and ATR, as well as by two downstream kinases, checkpoint kinases 1 and 2 (Chk1 and Chk2; encoded by CHEK1 and CHEK2, respectively). After their activation, both ATM and ATR upregulate cell cycle checkpoint pathways, inducing cell cycle arrest and DNA repair. ATM and ATR respond to different types of DNA lesions, to which they are recruited through specific co-factors; ATM responds primarily to DNA double-strand breaks (DSBs) (Paull, 2015), whereas ATR protects the integrity of replicating chromosomes (Branzei and Foiani, 2008). ATR is also activated by DSBs, however, through a mechanism that depends on ATM and the MRE11RAD50-NBS1 (MRN) complex (Doksani et al., 2009; Jazayeri et al., 2006). As will be discussed below, recent studies suggest that ATM and ATR also act in response to other cellular stresses, and that they might control cell pathways that do not converge on DNA repair mechanisms but that instead maintain cell homeostasis.

\section{ATM and ATR are members of the PIKK family}

ATM and ATR belong to the PIKK family together with mTOR, human suppressor of morphogenesis in genitalia-1 (SMG-1), DNA-PK catalytic subunit (DNAPKcs; encoded by PRKDC), and transformation/transcription-associated protein (TRRAP) (Lovejoy and Cortez, 2009). PIKK-family members share similarity in their kinase domains with the catalytic loops of class-I PI3K and are therefore categorized separately from the classic protein kinases. In addition, PIKK enzymes have a conserved FRAP-ATM-TRRAP (FAT), PIKK-regulatory domain (PRD) and FAT carboxy-terminal (FATC) domains, as well as an $\mathrm{N}$-terminus that bears numerous $\alpha$-helical Huntingtin, elongation factor 3, protein phosphatase 2A, TOR1 (HEAT) repeat motifs (Lovejoy and Cortez, 2009). The FAT domain is at the N-terminus of the kinase domain, whereas the FATC domain lies in its C-terminus (see poster). The PRD, FAT and FATC regions are crucial for ATR and ATM activation, and mutations in these regions can hamper their kinase activity (Bakkenist and Kastan, 2003; Liu et al., 2011; Mordes and Cortez, 2008; Nam and Cortez, 2011; Sun et al., 2005). The N-terminal HEAT repeats act as a scaffold; they mediate the interactions of ATM and ATR with proteins that regulate their catalytic activity and have an important role in their stability (see poster) (Perry and Kleckner, 2003). The HEAT repeats can also act as elastic connectors that undergo deformation following mechanical stimulation and regulate protein activity (Grinthal et al., 2010). As is the case for other PI3K-family members, PIKKs exist as homo- or heterodimers, and dimerization influences their stability and kinase activity. Accordingly, ATM forms dimers or oligomers under non-stress conditions and it is released in monomeric form following induction of stress (Bakkenist and Kastan, 2003). ATR forms a heterodimer with its obligatory partner ATR-interacting protein (ATRIP) (Cortez et al., 2001); this heterodimerization stabilizes ATR, although the interaction with ATRIP does not appear to be very strong (UnsalKacmaz and Sancar, 2004).

\section{ATR activation}

ATR is activated in response to a variety of DNA lesions that induce the formation of single-strand (ss)DNA (Cimprich and Cortez, 2008; Zou and Elledge, 2003). ATR activation is a multistep process, because the ATR-ATRIP heterodimer is unable to interact with DNA directly, and depends on nucleofilaments that are formed between the replication protein A heterotrimer (RPA) and ssDNA for DNA binding (Zou and Elledge, 2003). ATRassociated ATRIP interacts directly with ssDNA-bound RPA and so promotes ATR localization to sites of replication stress and DNA damage (Zou and Elledge, 2003) (see poster). It has recently been suggested that pre-mRNA processing factor 19 (PRP19)assisted ubiquitylation of RPA facilitates ATRIP binding to damaged DNA (Maréchal et al., 2014), which leads to partial ATR activation (Ashton et al., 2013). The RPA-assisted ATRIP-ATR complex then interacts with the DNA-damage-specific RAD9RAD1-HUS1 clamp (also called 9-1-1) that is bound at junctions between ssDNA and double-strand (ds)DNA (Ellison and Stillman, 2003). 9-1-1 itself is loaded onto the ssDNA-dsDNA junction by the clamp loader complex, RAD17-RFC, which is facilitated by RPA (Ellison and Stillman, 2003; Zou et al., 2003). This is followed by phosphorylation of the 9-1-1 subunit RAD9 on residue S387, which enables the association of DNA topoisomerase 2-binding protein 1 (TopBP1) with the FATC domain of ATR (St. Onge et al., 2003), leading to ATR activation (Choi et al., 2010) (see poster). Furthermore, TopBP1 can interact with both phosphorylated or unphosphorylated 9-1-1 complexes (Delacroix et al., 2007; Lee and Dunphy, 2010; Lee et al., 2007), and, moreover, its interaction with 9-1-1 can be mediated by other proteins such as RHINO ( $\operatorname{Rad} 9$, Rad1, Hus1 interacting nuclear orphan, encoded by RHNO1) (Cotta-Ramusino et al., 2011). A recent study has confirmed the function of RHINO in ATR activation following genotoxic stress, but also showed that RHINO is dispensable for the interaction of TopBP1 with the 9-1-1 complex (Lindsey-Boltz et al., 2015) (see poster). Importantly, the ATR-activation domain in TopBP1 can also mediate ATR activation in the absence of DNA damage or other known ATR activators, and so can initiate checkpoint signaling in the absence of DNA damage (Toledo et al., 2008). Although the current notion is that ATR is activated by RPA-ssDNA nucleofilaments, some studies appear to contradict this model because they have found RPA to be dispensable for ATR activation and subsequent Chk1 phosphorylation following genotoxic stress (Ball et al., 2005; Dodson et al., 2004). Moreover, the phenotypes of cells that have been depleted of RAD9 and of HUS1-depleted cells do not fully recapitulate those of cells with defective ATR signaling (Hopkins et al., 2004; Weiss et al., 2000), suggesting that RAD9 and HUS1 might be redundant for some of the ATR functions, or that ATR has other functions that do not require the 9-1-1 complex.

\section{ATM activation}

The mechanisms of ATM activation after DSB formation have recently been reviewed elsewhere (Paull, 2015). ATM activation comprises mainly the formation of ATM monomers and activation of the MRN-ATM signaling axis, as discussed below. How exactly DSBs recruit activators of ATM that induce its binding to DSBs, nonetheless, remains unclear.

Under non-stress conditions, ATM is inactive and exists in the form of a multimer (a dimer or higher order multimer) (Bakkenist 
and Kastan, 2003); like other PI3Ks, it requires a stimulus for activation. In human cells, following DNA damage, ATM undergoes autophosphorylation at residue S1981 in its FAT domain, which results in the simultaneous dissociation of the ATM homodimers (Bakkenist and Kastan, 2003) (see poster). An S1981A mutation renders ATM a dominant-negative protein, triggering DDR in response to DSB formation, which highlights the importance of autophosphorylation-mediated monomerization for ATM function (see poster). Phosphorylation of S1981 also stabilizes ATM at damaged DNA regions (So et al., 2009). Autophosphorylation of ATM at residues S367 and S1893 also contributes to its activation (Kozlov et al., 2006), although mutagenesis of the corresponding residues S367, S1899 and S1987 in murine ATM has no impact on ATM activation following induction of DNA damage in vivo (Daniel et al., 2008). In Xenopus extracts, ATM autophosphorylation is not involved in MRN-mediated ATM monomerization, ATM activation and its recruitment to DSBs (Lee and Paull, 2005). Taken together, these findings suggest that although ATM monomerization is essential for its functional activation, the role of autophosphorylation in activation might not be conserved across species. Among other ATM-activating steps, the acetylation of ATM at K3016 appears to be essential for its autophosphorylation and monomerization following DNA damage (Sun et al., 2005, 2007). This is mediated by the association of the histone acetyltransferase KAT5 with histone $\mathrm{H} 3$ trimethylated at Lys9 (H3K9me3), which is induced when KAT5 is phosphorylated by the kinase cellular (c)Abl (Kaidi and Jackson, 2013).

The MRN complex binds to dsDNA ends and provides a platform for ATM recruitment, which suggests that the MRN complex acts a sensor that initiates ATM activation (Lee and Paull, 2005). It has been proposed that ATM is stimulated by the MRN complex through its exo- and endonuclease activity, DNA tethering capability and conformational changes in the MRN complex that occur after DNA binding (Carson et al., 2003; Dupré et al., 2006; Lee and Paull, 2004; You et al., 2005). In addition, the interaction of ATM with the MRN component NBS1 (also known $N B N$ ) as is crucial for its recruitment to DSBs (Falck et al., 2005). Recent observations also suggest that the nuclease activity of MRE11 in the MRN complex is dispensable for ATM activation; instead, the coiled-coil domain and zinc hook in RAD50, and the ATP-driven conformational changes in the MRN complex that help to position the MRN complex in its functional conformation assist ATM activation by participating in DNA binding (Lee et al., 2013). Recent work has demonstrated that in the absence of $\mathrm{Ku}$ (encoded by XRCC6), the MRN complex is dispensable for ATM activation and its recruitment to DSBs, and for $\mathrm{G} 2 / \mathrm{M}$ checkpoint activation following DNA damage (Hartlerode et al., 2015); however, the MRN complex remains to be vital for the ATM-dependent DDR (Hartlerode et al., 2015). Nonetheless, the exact mechanisms through which MRN activates ATM in a DSB-dependent manner remain to be elucidated. Dephosphorylation of ATM by the protein phosphatases PP2A (Goodarzi et al., 2004), PP1 (Peng et al., 2010), Wip1 (also known as PPM1D) (Shreeram et al., 2006) and PP5 (Ali et al., 2004) might also be relevant for its activation.

\section{Signaling outputs of ATR and ATM}

Phosphorylation of downstream-acting proteins is at the heart of ATR and ATM signaling in response to cell stress events. Both kinases phosphorylate proteins on S/TQ motifs (Kim et al., 1999) and initiate widespread cell responses through phosphorylation of downstream effector proteins. Much of the knowledge gained with regard to ATR and ATM signaling cascades has been derived from the treatment of various cell types with high doses of DNA-damaging agents, which result in a burst of ATR and ATM activity, and downstream signaling. These studies might, nonetheless, underestimate the impact of ATR- and ATMmediated phosphorylation events that are elicited under more physiological conditions, particularly in light of the accumulating evidence that suggests that ATM- and ATR-mediated pathways are not restricted to nuclear events and DDR (see poster). Screens for S/TQ-containing substrates of ATR and ATM following DNA damage have also revealed putative substrates outside of the nucleus, as well as factors that are not directly linked to DNA repair processes (Matsuoka et al., 2007; Mu et al., 2007; Paulsen et al., 2009), although the functional relevance of many of these phosphorylation events remains to be determined. Intriguingly, DNA-PK has also been located at the Golgi, reinforcing the possibility that other PIKKs might also function outside of the nucleus (Farber-Katz et al., 2014).

In the following sections, we will discuss ATR and ATM signaling pathways in response to genotoxic stress, as well as in other cell-stress conditions, and outline how targeting of ATR and ATM could be employed for cancer therapy.

\section{ATR in replication stress}

Activation of the ATR-ATRIP complex (which is loaded onto DNA together with TopBP1) initiates a signaling cascade that coordinates cell cycle progression with DNA metabolic processes. ATR activity is necessary both for the stabilization of stalled replication forks and for fork restart following replication stress. On one hand, ATR inhibition results in the increased firing of origins in the absence of DNA damage (Shechter et al., 2004), but on the other hand, under replication stress, ATR-dependent phosphorylation of 'Fanconi anemia, complementation group I' (FANC1) inhibits the firing of dormant origins (Chen et al., 2015b). In addition, ATR deficiency in aphidicholine-treated cells causes incomplete replication of regions with fragile sites (Casper et al., 2002; Paulsen and Cimprich, 2007). When a replication fork encounters a gene that is being transcribed, the Mec1/ATR pathway phosphorylates nucleoporin components to release the transcribed chromatin, which is attached to the nuclear envelope (Bermejo et al., 2011), thereby preventing torsional-stressinduced fork reversal. Hence, the ATR response ensures robust replication through different means - by stabilizing replication forks (Paulsen and Cimprich, 2007), preventing fragile-site expression (Casper et al., 2002; Cha and Kleckner, 2002), influencing replication origin firing (Chen et al., 2015b; Shechter et al., 2004) and also coordinating replication with transcription (Bermejo et al., 2011), as well as by triggering the replication stress response (Flynn and Zou, 2011) (see poster). Under conditions of replication stress, a balance between the amounts of RPA and ssDNA appears to be crucial for the stability of the replication fork (Toledo et al., 2013). Accordingly, ssDNA uncoating owing to RPA paucity results in collapse of the replication fork and the generation of DSBs (Toledo et al., 2013).

\section{ATR in cell cycle regulation}

ATR also influences DNA repair processes, such as the repair of DSBs, nucleotide excision repair (NER) and inter-strand crosslink repair (ICL) (reviewed in Cimprich and Cortez, 2008). The bestcharacterized ATR effector, to date, is Chk1 (Zhao and PiwnicaWorms, 2001), which is activated through ATR-mediated phosphorylation at residues S317 and S345 (Liu et al., 2000) in a reaction that is stimulated by claspin binding to Chk1 (Lindsey- 
Boltz et al., 2009), by the 9-1-1 complex (Liu et al., 2012; Wang et al., 2006) and RHINO (Lindsey-Boltz et al., 2015), as well as by other factors (Nam and Cortez, 2011) (see poster). Chk1 activation stabilizes the chromatin-bound CDC7-DBF4 apoptosis signalregulating kinase (ASK) complex, which assists in replication and origin firing (Yamada et al., 2013). Chk1 affects progression through $\mathrm{S}$ phase at the level of origin firing, replication elongation and fork integrity (Brown and Baltimore, 2003; Heffernan et al., 2007; Petermann et al., 2006, 2010; Segurado and Diffley, 2008; Zhao et al., 2002). In addition, activated Chk1 also has an effect on S-phase progression through phosphorylation of CDC25 and regulation of cyclin-dependent kinases (CDKs) (Sanchez et al., 1997). The ATR-mediated Chk1 pathway also has a central role in preventing cells from entering into mitosis with unreplicated or damaged DNA (Brown and Baltimore, 2003). Chk1-dependent sequestration of $\mathrm{CDC} 25 \mathrm{C}$ into the cytoplasm and degradation of CDC25A maintains CDK1 in its inactive state, resulting in $\mathrm{G} 2 / \mathrm{M}$ arrest (Mailand et al., 2002; Nghiem et al., 2001; Peng et al., 1997; Sanchez et al., 1997).

Cells that express kinase-dead ATR mutants undergo premature chromosome condensation and entry into mitosis (Nghiem et al., 2001). Other ATR targets, such as the helicase SMARCAL1, whose fork regression activity is compromised after phosphorylation by ATR, thereby preventing aberrant fork processing, thus have important roles in the response of ATR to replication stress (Couch et al., 2013). ATR is also activated in G1 following $\gamma$ irradiation in order to facilitate DNA repair (Gamper et al., 2013). It has also been suggested that ATR has a role in the physical separation of cells during cytokinesis through Chk1-mediated phosphorylation of Aurora B (encoded by AURKB) (Mackay and Ullman, 2015) (see poster), a known mediator of furrow cleavage that promotes cytokinesis (Marumoto et al., 2005). We have recently shown that ATR responds to osmotic and mechanical stress, and that cells derived from individuals with Seckel syndrome fail to coordinate chromatin condensation with nuclear envelope breakdown (Kumar et al., 2014) (see poster). This process does not appear to involve DNA-damage sensing and might be mediated through the elastic properties of the N-terminal ATR HEAT repeats, which could act as mechanosensors (Grinthal et al., 2010). However, more work is required to elucidate the mechanism of ATR activation in response to mechanical stress.

\section{Cellular effects of ATM signaling}

ATM activation has a pivotal position in DDR, and is triggered in response to oxidative stress (Okuno et al., 2012) and DSB formation (Lee and Paull, 2005; van Gent et al., 2001). A recent report has also suggested that a very early ATM activation event in response to replication stress - the sensing of regressed replication forks - is triggered by the FBH1 (encoded by $F B X O 18$ ) helicase (Fugger et al., 2015). After its activation, ATM induces a wide spectrum of signal transduction pathways that connect processes involved in DNA repair, cell metabolism, bioenergetics, as well as protein translation and transcription. The best-characterized effector of ATM signaling is Chk2, which is phosphorylated at residue T62 by ATM following DSB formation (Chaturvedi et al., 1999; Matsuoka et al., 1998, 2000). In addition to Chk2, ATM-dependent DSB repair also involves direct phosphorylation of MRE11, RAD9, RAD50, p53, NBS1, DNA-PKs, CtIP (encoded by RBBP8) and many other proteins, as recently reviewed elsewhere (Shiloh and Ziv, 2013). ATM-mediated pathways have also been shown to be involved in chromatin relaxation (Goodarzi et al., 2008; Moyal et al., 2011; Polo et al., 2010; Ziv et al., 2006), nucleosome

\section{Box 1. Relevance of ATM and ATR signaling in cancer}

Both ATM and ATR signaling impact on tumorigenesis; in fact, in the early phase of tumorigenesis, both ATM and ATR provide a barrier to tumor progression by inducing cell cycle arrest and apoptosis (Bartek et al., 2007; Bartkova et al., 2006; Halazonetis et al., 2008; Pusapati et al., 2006). In pre-cancerous lesions, both the ATM and ATR pathways are activated, thereby helping the cell to mount a resistance to tumor development (Gorgoulis et al., 2005; Negrini et al., 2010). In addition, loss-of-function mutations or deletions of ATM or ATR, as well as their reduced kinase activity or expression levels, or deletions of components of their downstream pathways, all promote cell survival and result in a multi-fold increase in the propensity of a cell to become cancerous, and in an acceleration of tumor progression (Nevanlinna and Bartek, 2006; Spring et al., 2002; Vahteristo et al., 2002; Bertoni et al., 1999; Greenman et al., 2007; Guarini et al., 2012; Hollestelle et al., 2010; Menoyo et al., 2001; Reiman et al., 2011; Renwick et al., 2006; Roberts et al., 2012; Squatrito et al., 2010; Tanaka et al., 2012; Zighelboim et al., 2015,2009 ) (see poster). In particular, in ATM, distinct mutations have been found that cause different human malignancies, including lung cancer, breast cancer, colon cancer, lymphocytic leukemia, pancreatic cancer, and head and neck cancer, among others (Ding et al., 2008; Goldgar et al., 2011; Guarini et al., 2012; Roberts et al., 2012; Seshagiri et al., 2012) (see poster). Homozygous loss-of-function mutations or deletion of ATR or Chk1 have not yet been reported; however, there are sporadic studies that show mutations in ATR or Chk1 in certain cancer types (Kim et al., 2007; Lewis et al., 2007; Liu et al., 2008; Menoyo et al., 2001; Zighelboim et al., 2009) (see poster), suggesting that the ATRChk1 axis cannot be generalized as a canonical tumor suppressor pathway.

Although the current view in the field is that ATM and ATR signaling inhibits tumor progression rather than promoting cancer (Bartkova et al., 2006; Gorgoulis et al., 2005; Halazonetis et al., 2008), there has been a number of recent reports of overexpression of ATM or ATR, or of activation of the downstream pathways in different cancers (Albiges et al., 2014; Bhatia et al., 2013; Hoglund et al., 2011; Mahajan et al., 2012; Sarmento et al., 2015; Tho et al., 2012; Vadnais et al., 2012; Verlinden et al., 2007; Xu et al., 2013) (see poster). Of note, the addition of an extra allele of Chk1 has even been found to promote Ras- or E1A-mediated transformation more efficiently in comparison to such transformation of wild-type littermates (Lopez-Contreras et al., 2012), suggesting that the ATR-Chk1 axis has a pro-malignant transformation role.

remodeling (Goodarzi et al., 2011), and activation of p53, NF- $\kappa \mathrm{B}$ and microRNAs (Turenne et al., 2001; Wu et al., 2006; Zhang et al., 2011) in order to regulate the transcription of genes that are needed to modulate cell responses following DNA damage (see poster).

\section{Box 2. ATR and ATM as targets for cancer therapy}

Considering their roles as tumor suppressors as well as facilitators in mediating responses to DNA damage, ATM and ATR have long been considered as potential drug targets for cancer therapy; however, the generation of specific inhibitors for ATM and ATR has remained a difficult task. The compounds that have initially been used to inhibit ATM and ATR are the pan-PI3K inhibitors LY294002, caffeine (Sarkaria et al., 1999) and wortmannin (Sarkaria et al., 1998). Recently, more specific compounds have been identified (Batey et al., 2013; Fokas et al., 2012; Guo et al., 2014; Toledo et al., 2011). ATM-specific inhibitors identified to date include CP-466722, KU-55933, KU-60019 and KU-559403, whereas the ATR-specific inhibitors are schisandrin B, VE-821, VE-822, AZ20 and AZD6738. A combination of ATM or ATR inhibitors, with chemotherapeutic drugs or radiotherapy has been highly successful in the treatment of many types of cancer. A recent review provides a detailed update on ATM and ATR inhibitors, and their potential as drug targets (Weber et al., 2014). 
Another recent report shows that R-loop-mediated ATM activation regulates the expression of target genes and accelerates alternative pre-mRNA splicing in a genome-wide manner to produce new gene products following irradiation with ultraviolet C (UVC) (Tresini et al., 2015).

ATM also mediates nuclear and cytoplasmic signaling cascades that are unrelated to DNA repair events but are instead involved in maintaining cell homeostasis, such as insulin signaling (Yang and Kastan, 2000), as well as in responses to hyperthermia (Hunt et al., 2007), hypoxia (Bencokova et al., 2009) and hypotonic stress (Bakkenist and Kastan, 2003; Kanu and Behrens, 2007). ATM is also activated in the absence of DNA damage upon mitotic spindle checkpoint activation (Yang et al., 2011) and during hematopoietic stem cell survival (Ito et al., 2004; Maryanovich et al., 2012). ATM activation in response to reactive oxygen species (ROS) is independent of the MRN complex (Guo et al., 2010) and involves ATM-interacting protein (ATMIN) (Kanu and Behrens, 2007), suggesting that the NBS1 subunit in the MRN complex and ATMIN respond to distinct stimuli (Zhang et al., 2012). ROS-mediated ATM signaling represses mTORC1 signaling and, therefore, cell growth and proliferation through activation of TSC2 (a negative regulator of mTOR) by liver kinase B1 (LKB1, also known as STK11) and AMP-dependent protein kinases (AMPKs) (Alexander et al., 2010) (see poster).

ATM activation also affects mitochondrial physiology and function by helping to eliminate defective mitochondria through mitophagy, thus providing a link between ROS metabolism and mitochondrial dysfunction (Valentin-Vega et al., 2012). In accordance with this, fibroblasts from individuals with ataxia telangiectasia have higher ROS levels and are sensitive to oxidative stress (Ito et al., 2004; Reichenbach et al., 2002), which suggests that ATM not only protects cells from oxidative damage but that it also maintains low endogenous ROS levels. Interestingly, ROS-induced ATM activation has been reported to assist in cell migration and invasion through interleukin 8 (IL-8), suggesting that ATM might also function to promote tumor progression (Chen et al., 2015a). Although there is emerging evidence for a role of ATM in promoting tumorigenesis, early in tumorigenesis, ATM signaling provides a barrier to activated oncogenes and tumor progression, rather than promoting cancer (Bartkova et al., 2005; Gorgoulis et al., 2005; Halazonetis et al., 2008) (see Box 1), and ATM has been one of the prime drug targets for cancer therapy (see Box 2). Under hypoxia, increased replication stress and $\mathrm{H} 3 \mathrm{~K} 9 \mathrm{me} 3$ levels, together with repressed PP2A activity, facilitate ATM activation and prevent DSB formation, thereby enabling normal replication (Olcina et al., 2013). Activated ATM also phosphorylates and activates the transcriptional regulator hypoxia-inducible factor $1 \alpha(\mathrm{HIF} 1 \alpha)$, resulting in the upregulation of REDD1, a TSC2 activator; this leads to suppression of $\mathrm{mTORC} 1$ signaling and results in a decrease of anabolic processes and an increase in catabolic processes (Cam et al., 2010).

\section{Conclusions}

ATM and ATR kinases have been extensively studied with respect to roles in the DDR; here, key cofactors mediate their recruitment to DNA damage sites and contribute to the activation of DDR signaling. Recent findings suggest that both ATM and ATR have additional functions in maintaining cell homeostasis that are unrelated to the DNA-damage cascade. Further exploring the ATM- and ATR-mediated pathways that function in response to distinct stress conditions will help us to not only better understand the connections between ATR, ATM and mTOR signaling, but also to rationalize the use of ATR and ATM inhibitors in cancer therapy.

\section{Acknowledgements}

We are grateful to C. Mark (CNB and CSIC, Madrid, Spain) for editorial assistance.

\section{Competing interests}

The authors declare no competing or financial interests

\section{Funding}

P.A. held a pre-doctoral fellowship from the Council of Scientific and Industrial Research (CSIR). Work in the laboratory of A.K. is funded by the CSIR Indepth, Epigenetics in health and disease network projects. The laboratory of M.F. is supported by grants from Associazione Italiana per la Ricerca sul Cancro; Association for International Cancer Research; Telethon Foundation, Italy; Fondazione Centro Europeo Nanomedicina (CEN-Italy); Ministero dell'Istruzione Universitaria e della Ricerca. CSIR manuscript communication number 3304

\section{Cell science at a glance}

A high-resolution version of the poster is available for downloading at http://jcs. biologists.org/lookup/suppl/doi:10.1242/jcs.169730/-/DC1. Individual poster panels are available as JPEG files at http://jcs.biologists.org/lookup/suppl/doi:10.1242/jcs. 169730/-/DC2.

\section{References}

Albiges, L., Goubar, A., Scott, V., Vicier, C., Lefèbvre, C., Alsafadi, S., Commo, F., Saghatchian, M., Lazar, V., Dessen, P. et al. (2014). Chk1 as a new therapeutic target in triple-negative breast cancer. Breast 23, 250-258.

Alexander, A., Cai, S.-L., Kim, J., Nanez, A., Sahin, M., MacLean, K. H., Inoki, K., Guan, K.-L., Shen, J., Person, M. D. et al. (2010). ATM signals to TSC2 in the cytoplasm to regulate mTORC1 in response to ROS. Proc. Natl. Acad. Sci. USA 107, 4153-4158.

Ali, A., Zhang, J., Bao, S., Liu, I., Otterness, D., Dean, N. M., Abraham, R. T. and Wang, X.-F. (2004). Requirement of protein phosphatase 5 in DNA-damageinduced ATM activation. Genes Dev. 18, 249-254.

Ashton, N. W., Bolderson, E., Cubeddu, L., O'Byrne, K. J. and Richard, D. J. (2013). Human single-stranded DNA binding proteins are essential for maintaining genomic stability. BMC Mol. Biol. 14, 9.

Bakkenist, C. J. and Kastan, M. B. (2003). DNA damage activates ATM through intermolecular autophosphorylation and dimer dissociation. Nature 421, 499-506. Bakkenist, C. J. and Kastan, M. B. (2004). Initiating cellular stress responses. Cell 118, 9-17.

Ball, H. L., Myers, J. S. and Cortez, D. (2005). ATRIP binding to replication protein A-single-stranded DNA promotes ATR-ATRIP localization but is dispensable for Chk1 phosphorylation. Mol. Biol. Cell 16, 2372-2381.

Bartek, J., Bartkova, J. and Lukas, J. (2007). DNA damage signalling guards against activated oncogenes and tumour progression. Oncogene 26, 7773-7779. Bartkova, J., Hořejší, Z., Koed, K., Krämer, A., Tort, F., Zieger, K., Guldberg, P., Sehested, M., Nesland, J. M., Lukas, C. et al. (2005). DNA damage response as a candidate anti-cancer barrier in early human tumorigenesis. Nature 434 864-870.

Bartkova, J., Rezaei, N., Liontos, M., Karakaidos, P., Kletsas, D., Issaeva, N. Vassiliou, L.-V. F., Kolettas, E., Niforou, K., Zoumpourlis, V. C. et al. (2006). Oncogene-induced senescence is part of the tumorigenesis barrier imposed by DNA damage checkpoints. Nature 444, 633-637.

Batey, M. A., Zhao, Y., Kyle, S., Richardson, C., Slade, A., Martin, N. M. B., Lau, A., Newell, D. R. and Curtin, N. J. (2013). Preclinical evaluation of a novel ATM inhibitor, KU59403, in vitro and in vivo in p53 functional and dysfunctional models of human cancer. Mol. Cancer Ther. 12, 959-967.

Bencokova, Z., Kaufmann, M. R., Pires, I. M., Lecane, P. S., Giaccia, A. J. and Hammond, E. M. (2009). ATM activation and signaling under hypoxic conditions. Mol. Cell. Biol. 29, 526-537.

Bermejo, R., Capra, T., Jossen, R., Colosio, A., Frattini, C., Carotenuto, W. Cocito, A., Doksani, Y., Klein, H., Gómez-González, B. et al. (2011). The replication checkpoint protects fork stability by releasing transcribed genes from nuclear pores. Cell 146, 233-246.

Bertoni, F., Codegoni, A. M., Furlan, D., Tibiletti, M. G., Capella, C. and Broggini, M. (1999). CHK1 frameshift mutations in genetically unstable colorectal and endometrial cancers. Genes Chromosomes Cancer 26, 176-180.

Bhatia, N., Xiao, T. Z., Rosenthal, K. A., Siddiqui, I. A., Thiyagarajan, S., Smart, B., Meng, Q., Zuleger, C. L., Mukhtar, H., Kenney, S. C. et al. (2013). MAGE-C2 promotes growth and tumorigenicity of melanoma cells, phosphorylation of KAP1 and DNA damage repair. J. Invest. Dermatol. 133, 759-767.

Branzei, D. and Foiani, M. (2008). Regulation of DNA repair throughout the cell cycle. Nat. Rev. Mol. Cell Biol. 9, 297-308.

Brown, E. J. and Baltimore, D. (2003). Essential and dispensable roles of ATR in cell cycle arrest and genome maintenance. Genes Dev. 17, 615-628.

Cam, H., Easton, J. B., High, A. and Houghton, P. J. (2010). mTORC1 signaling under hypoxic conditions is controlled by ATM-dependent phosphorylation of HIF1alpha. Mol. Cell 40, 509-520. 
Carson, C. T., Schwartz, R. A., Stracker, T. H., Lilley, C. E., Lee, D. V. and Weitzman, M. D. (2003). The Mre11 complex is required for ATM activation and the G2/M checkpoint. EMBO J. 22, 6610-6620

Casper, A. M., Nghiem, P., Arlt, M. F. and Glover, T. W. (2002). ATR regulates fragile site stability. Cell 111, 779-789.

Cha, R. S. and Kleckner, N. (2002). ATR homolog Mec1 promotes fork progression, thus averting breaks in replication slow zones. Science 297, 602-606.

Chaturvedi, P., Eng, W. K., Zhu, Y., Mattern, M. R., Mishra, R., Hurle, M. R., Zhang, X., Annan, R. S., Lu, Q., Faucette, L. F. et al. (1999). Mammalian Chk2 is a downstream effector of the ATM-dependent DNA damage checkpoint pathway. Oncogene 18, 4047-4054.

Chen, W.-T., Ebelt, N. D., Stracker, T. H., Xhemalce, B., Van Den Berg, C. L. and Miller, K. M. (2015a). ATM regulation of IL-8 links oxidative stress to cancer cell migration and invasion. eLife 4, e07270.

Chen, Y.-H., Jones, M. J., Yin, Y., Crist, S. B., Colnaghi, L., Sims, R. J., III, Rothenberg, E., Jallepalli, P. V. and Huang, T. T. (2015b). ATR-mediated phosphorylation of $\mathrm{FANCl}$ regulates dormant origin firing in response to replication stress. Mol. Cell 58, 323-338.

Choi, J.-H., Lindsey-Boltz, L. A., Kemp, M., Mason, A. C., Wold, M. S. and Sancar, A. (2010). Reconstitution of RPA-covered single-stranded DNA-activated ATR-Chk1 signaling. Proc. Natl. Acad. Sci. USA 107, 13660-13665.

Cimprich, K. A. and Cortez, D. (2008). ATR: an essential regulator of genome integrity. Nat. Rev. Mol. Cell Biol. 9, 616-627.

Cimprich, K. A., Shin, T. B., Keith, C. T. and Schreiber, S. L. (1996). cDNA cloning and gene mapping of a candidate human cell cycle checkpoint protein. Proc. Natl. Acad. Sci. USA 93, 2850-2855.

Cortez, D., Guntuku, S., Qin, J. and Elledge, S. J. (2001). ATR and ATRIP partners in checkpoint signaling. Science 294, 1713-1716.

Cotta-Ramusino, C., McDonald, E. R., III, Hurov, K., Sowa, M. E., Harper, J. W. and Elledge, S. J. (2011). A DNA damage response screen identifies RHINO, a 9-1-1 and TopBP1 interacting protein required for ATR signaling. Science 332 1313-1317.

Couch, F. B., Bansbach, C. E., Driscoll, R., Luzwick, J. W., Glick, G. G., Betous, R., Carroll, C. M., Jung, S. Y., Qin, J., Cimprich, K. A. et al. (2013). ATR phosphorylates SMARCAL1 to prevent replication fork collapse. Genes Dev. 27 1610-1623

Daniel, J. A., Pellegrini, M., Lee, J.-H., Paull, T. T., Feigenbaum, L. and Nussenzweig, A. (2008). Multiple autophosphorylation sites are dispensable for murine ATM activation in vivo. J. Cell Biol. 183, 777-783.

Delacroix, S., Wagner, J. M., Kobayashi, M., Yamamoto, K.-i. and Karnitz, L. M. (2007). The Rad9-Hus1-Rad1 (9-1-1) clamp activates checkpoint signaling via TopBP1. Genes Dev. 21, 1472-1477.

Ding, L., Getz, G., Wheeler, D. A., Mardis, E. R., McLellan, M. D., Cibulskis, K., Sougnez, C., Greulich, H., Muzny, D. M., Morgan, M. B. et al. (2008). Somatic mutations affect key pathways in lung adenocarcinoma. Nature 455, 1069-1075.

Dodson, G. E., Shi, Y. and Tibbetts, R. S. (2004). DNA replication defects, spontaneous DNA damage, and ATM-dependent checkpoint activation in replication protein A-deficient cells. J. Biol. Chem. 279, 34010-34014.

Doksani, Y., Bermejo, R., Fiorani, S., Haber, J. E. and Foiani, M. (2009). Replicon dynamics, dormant origin firing, and terminal fork integrity after double-strand break formation. Cell 137, 247-258.

Dupré, A., Boyer-Chatenet, L. and Gautier, J. (2006). Two-step activation of ATM by DNA and the Mre11-Rad50-Nbs1 complex. Nat. Struct. Mol. Biol. 13 451-457.

Ellison, V. and Stillman, B. (2003). Biochemical characterization of DNA damage checkpoint complexes: clamp loader and clamp complexes with specificity for 5 recessed DNA. PLoS Biol. 1, e3.

Falck, J., Coates, J. and Jackson, S. P. (2005). Conserved modes of recruitment of ATM, ATR and DNA-PKcs to sites of DNA damage. Nature 434, 605-611.

Farber-Katz, S. E., Dippold, H. C., Buschman, M. D., Peterman, M. C., Xing, M., Noakes, C. J., Tat, J., Ng, M. M., Rahajeng, J., Cowan, D. M. et al. (2014). DNA damage triggers Golgi dispersal via DNA-PK and GOLPH3. Cell 156, 413-427.

Flynn, R. L. and Zou, L. (2011). ATR: a master conductor of cellular responses to DNA replication stress. Trends Biochem. Sci. 36, 133-140.

Fokas, E., Prevo, R., Pollard, J. R., Reaper, P. M., Charlton, P. A., Cornelissen, B. Vallis, K. A. Hammond, E. M., Olcina, M. M. Gillies McKenna, W. et al. (2012). Targeting ATR in vivo using the novel inhibitor VE-822 results in selective sensitization of pancreatic tumors to radiation. Cell Death Dis. 3, e441.

Fugger, K., Mistrik, M., Neelsen, K. J., Yao, Q., Zellweger, R., Kousholt, A. N., Haahr, P., Chu, W. K., Bartek, J., Lopes, M. et al. (2015). FBH1 catalyzes regression of stalled replication forks. Cell Rep. 10, 749-1757.

Gamper, A. M., Rofougaran, R., Watkins, S. C., Greenberger, J. S., Beumer, J. H. and Bakkenist, C. J. (2013). ATR kinase activation in G1 phase facilitates the repair of ionizing radiation-induced DNA damage. Nucleic Acids Res. 41, 10334-10344.

Goldgar, D. E., Healey, S., Dowty, J. G., Da Silva, L., Chen, X., Spurdle, A. B., Terry, M. B., Daly, M. J., Buys, S. M., Southey, M. C. et al. (2011). Rare variants in the ATM gene and risk of breast cancer. Breast Cancer Res. 13, R73.

Goodarzi, A. A., Jonnalagadda, J. C., Douglas, P., Young, D., Ye, R., Moorhead, G. B. G., Lees-Miller, S. P. and Khanna, K. K. (2004). Autophosphorylation of ataxia-telangiectasia mutated is regulated by protein phosphatase $2 \mathrm{~A}$. EMBO J. 23, 4451-4461

Goodarzi, A. A., Noon, A. T., Deckbar, D., Ziv, Y., Shiloh, Y., Löbrich, M. and Jeggo, P. A. (2008). ATM signaling facilitates repair of DNA double-strand breaks associated with heterochromatin. Mol. Cell 31, 167-177.

Goodarzi, A. A., Kurka, T. and Jeggo, P. A. (2011). KAP-1 phosphorylation regulates $\mathrm{CHD} 3$ nucleosome remodeling during the DNA double-strand break response. Nat. Struct. Mol. Biol. 18, 831-839.

Gorgoulis, V. G., Vassiliou, L.-V., Karakaidos, P., Zacharatos, P., Kotsinas, A. Liloglou, T., Venere, M., Ditullio, R. A., Jr., Kastrinakis, N. G., Levy, B. et al. (2005). Activation of the DNA damage checkpoint and genomic instability in human precancerous lesions. Nature 434, 907-913

Greenman, C., Stephens, P., Smith, R., Dalgliesh, G. L., Hunter, C., Bignell, G., Davies, H., Teague, J., Butler, A., Stevens, C. et al. (2007). Patterns of somatic mutation in human cancer genomes. Nature 446, 153-158.

Grinthal, A., Adamovic, I., Weiner, B., Karplus, M. and Kleckner, N. (2010) PR65, the HEAT-repeat scaffold of phosphatase PP2A, is an elastic connecto that links force and catalysis. Proc. Natl. Acad. Sci. USA 107, 2467-2472.

Guarini, A., Marinelli, M., Tavolaro, S., Bellacchio, E., Magliozzi, M., Chiaretti, S., De Propris, M. S., Peragine, N., Santangelo, S., Paoloni, F. et al. (2012) ATM gene alterations in chronic lymphocytic leukemia patients induce a distinc gene expression profile and predict disease progression. Haematologica 97 $47-55$.

Guo, Z., Kozlov, S., Lavin, M. F., Person, M. D. and Paull, T. T. (2010). ATM activation by oxidative stress. Science 330, 517-521.

Guo, K., Shelat, A. A., Guy, R. K. and Kastan, M. B. (2014). Development of a cellbased, high-throughput screening assay for ATM kinase inhibitors. J. Biomol. Screen 19, 538-546.

Halazonetis, T. D., Gorgoulis, V. G. and Bartek, J. (2008). An oncogene-induced DNA damage model for cancer development. Science 319, 1352-1355.

Hartlerode, A. J., Morgan, M. J., Wu, Y., Buis, J. and Ferguson, D. O. (2015) Recruitment and activation of the ATM kinase in the absence of DNA-damage sensors. Nat. Struct. Mol. Biol. 22, 736-743

Heffernan, T. P., Unsal-Kacmaz, K., Heinloth, A. N., Simpson, D. A., Paules, R. S., Sancar, A., Cordeiro-Stone, M. and Kaufmann, W. K. (2007). Cdc7-Dbf4 and the human S checkpoint response to UVC. J. Biol. Chem. 282, 9458-9468.

Hoglund, A., Nilsson, L. M., Muralidharan, S. V., Hasvold, L. A., Merta, P., Rudelius, M., Nikolova, V., Keller, U. and Nilsson, J. A. (2011). Therapeutic implications for the induced levels of Chk1 in Myc-expressing cancer cells. Clin Cancer Res. 17, 7067-7079.

Hollestelle, A., Wasielewski, M., Martens, J. W. M. and Schutte, M. (2010) Discovering moderate-risk breast cancer susceptibility genes. Curr. Opin. Genet Dev. 20, 268-276.

Hopkins, K. M., Auerbach, W., Wang, X. Y., Hande, M. P., Hang, H., Wolgemuth, D. J., Joyner, A. L. and Lieberman, H. B. (2004). Deletion of mouse rad 9 causes abnormal cellular responses to DNA damage, genomic instability, and embryonic lethality. Mol. Cell. Biol. 24, 7235-7248.

Hunt, C. R., Pandita, R. K., Laszlo, A., Higashikubo, R., Agarwal, M., Kitamura, T., Gupta, A., Rief, N., Horikoshi, N., Baskaran, R. et al. (2007). Hyperthermia activates a subset of ataxia-telangiectasia mutated effectors independent of DNA strand breaks and heat shock protein 70 status. Cancer Res. 67, 3010-3017.

Ito, K., Hirao, A., Arai, F., Matsuoka, S., Takubo, K., Hamaguchi, I., Nomiyama, K., Hosokawa, K., Sakurada, K., Nakagata, N. et al. (2004). Regulation of oxidative stress by ATM is required for self-renewal of haematopoietic stem cells. Nature 431, 997-1002.

Jazayeri, A., Falck, J., Lukas, C., Bartek, J., Smith, G. C. M., Lukas, J. and Jackson, S. P. (2006). ATM- and cell cycle-dependent regulation of ATR in response to DNA double-strand breaks. Nat. Cell Biol. 8, 37-45.

Kaidi, A. and Jackson, S. P. (2013). KAT5 tyrosine phosphorylation couples chromatin sensing to ATM signalling. Nature 498, 70-74.

Kanu, N. and Behrens, A. (2007). ATMIN defines an NBS1-independent pathway of ATM signalling. EMBO J. 26, 2933-2941.

Kim, S.-T., Lim, D.-S., Canman, C. E. and Kastan, M. B. (1999). Substrate specificities and identification of putative substrates of ATM kinase family members. J. Biol. Chem. 274, 37538-37543.

Kim, C. J., Lee, J. H., Song, J. W., Cho, Y. G., Kim, S. Y., Nam, S. W., Yoo, N. J., Park, W. S. and Lee, J. Y. (2007). Chk1 frameshift mutation in sporadic and hereditary non-polyposis colorectal cancers with microsatellite instability. Eur. J. Surg. Oncol. 33, 580-585.

Kozlov, S. V., Graham, M. E., Peng, C., Chen, P., Robinson, P. J. and Lavin, M. F. (2006). Involvement of novel autophosphorylation sites in ATM activation. EMBO J. 25, 3504-3514

Kumar, A., Mazzanti, M., Mistrik, M., Kosar, M., Beznoussenko, G. V., Mironov, A. A., Garrè, M., Parazzoli, D., Shivashankar, G. V., Scita, G. et al. (2014). ATR mediates a checkpoint at the nuclear envelope in response to mechanical stress. Cell 158, 633-646.

Lavin, M. F. (2008). Ataxia-telangiectasia: from a rare disorder to a paradigm for cell signalling and cancer. Nat. Rev. Mol. Cell Biol. 9, 759-769. 
Lee, J. and Dunphy, W. G. (2010). Rad17 plays a central role in establishment of the interaction between TopBP1 and the Rad9-Hus1-Rad1 complex at stalled replication forks. Mol. Biol. Cell 21, 926-935

Lee, J.-H. and Paull, T. T. (2004). Direct activation of the ATM protein kinase by the Mre11/Rad50/Nbs1 complex. Science 304, 93-96.

Lee, J. H. and Paull, T. T. (2005). ATM activation by DNA double-strand breaks through the Mre11-Rad50-Nbs1 complex. Science 308, 551-554.

Lee, J., Kumagai, A. and Dunphy, W. G. (2007). The Rad9-Hus1-Rad1 checkpoint clamp regulates interaction of TopBP1 with ATR. J. Biol. Chem. 282, 28036-28044.

Lee, J.-H., Mand, M. R., Deshpande, R. A., Kinoshita, E., Yang, S.-H., Wyman, C. and Paull, T. T. (2013). Ataxia telangiectasia-mutated (ATM) kinase activity is regulated by ATP-driven conformational changes in the Mre11/Rad50/Nbs 1 (MRN) complex. J. Biol. Chem. 288, 12840-12851.

Lewis, K. A., Bakkum-Gamez, J., Loewen, R., French, A. J., Thibodeau, S. N. and Cliby, W. A. (2007). Mutations in the ataxia telangiectasia and rad3-relatedcheckpoint kinase 1 DNA damage response axis in colon cancers. Genes Chromosomes Cancer 46, 1061-1068.

Lindsey-Boltz, L. A., Sercin, O., Choi, J.-H. and Sancar, A. (2009). Reconstitution of human claspin-mediated phosphorylation of Chk1 by the ATR (ataxia telangiectasia-mutated and rad3-related) checkpoint kinase. J. Biol. Chem. 284 33107-33114.

Lindsey-Boltz, L. A., Kemp, M. G., Capp, C. and Sancar, A. (2015). RHINO forms a stoichiometric complex with the 9-1-1 checkpoint clamp and mediates ATR Chk1 signaling. Cell Cycle 14, 99-108

Liu, Q., Guntuku, S., Cui, X. S., Matsuoka, S., Cortez, D., Tamai, K., Luo, G. Carattini-Rivera, S., DeMayo, F., Bradley, A. et al. (2000). Chk1 is an essential kinase that is regulated by Atr and required for the $G(2) / M$ DNA damage checkpoint. Genes Dev. 14, 1448-1459.

Liu, A., Takakuwa, T., Fujita, S., Luo, W.-J., Tresnasari, K., Van den Berg, A., Poppema, S. and Aozasa, K. (2008). ATR alterations in Hodgkin's lymphoma. Oncol. Rep. 19, 999-1005.

Liu, S., Shiotani, B., Lahiri, M., Maréchal, A., Tse, A., Leung, C. C. Y., Glover, J. N. M., Yang, X. H. and Zou, L. (2011). ATR autophosphorylation as a molecula switch for checkpoint activation. Mol. Cell 43, 192-202.

Liu, S., Song, N. and Zou, L. (2012). The conserved C terminus of Claspin interacts with Rad 9 and promotes rapid activation of Chk1. Cell Cycle 11, 2711-2716.

Lopez-Contreras, A. J., Gutierrez-Martinez, P., Specks, J., Rodrigo-Perez, S. and Fernandez-Capetillo, O. (2012). An extra allele of Chk1 limits oncogeneinduced replicative stress and promotes transformation. J. Exp. Med. 209 455-461.

Lovejoy, C. A. and Cortez, D. (2009). Common mechanisms of PIKK regulation DNA Repair 8, 1004-1008.

Mackay, D. R. and Ullman, K. S. (2015). ATR and a Chk1-Aurora B pathway coordinate postmitotic genome surveillance with cytokinetic abscission. Mol. Biol. Cell 26, 2217-2226.

Mahajan, K., Coppola, D., Rawal, B., Chen, Y. A., Lawrence, H. R., Engelman R. W., Lawrence, N. J. and Mahajan, N. P. (2012). Ack1-mediated androgen receptor phosphorylation modulates radiation resistance in castration-resistan prostate cancer J. Biol Chem. 287, 22112-22122.

Mailand, N., Podtelejnikov, A. V., Groth, A., Mann, M., Bartek, J. and Lukas, J. (2002). Regulation of $\mathrm{G} 2 / \mathrm{M}$ events by Cdc25A through phosphorylationdependent modulation of its stability. EMBO J.21,5911-5920.

Maréchal, A., Li, J.-M., Ji, X. Y., Wu, C.-S., Yazinski, S. A., Nguyen, H. D., Liu, S., Jiménez, A. E., Jin, J. and Zou, L. (2014). PRP19 transforms into a sensor of RPA-sSDNA after DNA damage and drives ATR activation via a ubiquitinmediated circuitry. Mol. Cell 53, 235-246.

Marumoto, T., Zhang, D. and Saya, H. (2005). Aurora-A - a guardian of poles. Nat Rev. Cancer $5,42-50$.

Maryanovich, M., Oberkovitz, G., Niv, H., Vorobiyov, L., Zaltsman, Y., Brenner, O., Lapidot, T., Jung, S. and Gross, A. (2012). The ATM-BID pathway regulates quiescence and survival of haematopoietic stem cells. Nat. Cell Biol. 14, 535-541.

Matsuoka, S., Huang, M. and Elledge, S. J. (1998). Linkage of ATM to cell cycle regulation by the Chk2 protein kinase. Science 282, 1893-1897.

Matsuoka, S., Rotman, G., Ogawa, A., Shiloh, Y., Tamai, K. and Elledge, S. J. (2000). Ataxia telangiectasia-mutated phosphorylates Chk2 in vivo and in vitro. Proc. Natl. Acad. Sci. USA 97, 10389-10394

Matsuoka, S., Ballif, B. A., Smogorzewska, A., McDonald, E. R., III, Hurov, K. E. Luo, J., Bakalarski, C. E., Zhao, Z., Solimini, N., Lerenthal, Y. et al. (2007) ATM and ATR substrate analysis reveals extensive protein networks responsive to DNA damage. Science 316, 1160-1166.

Menoyo, A., Alazzouzi, H., Espin, E., Armengol, M., Yamamoto, H. and Schwartz, S., Jr (2001). Somatic mutations in the DNA damage-response genes ATR and CHK1 in sporadic stomach tumors with microsatellite instability. Cancer Res. 61, 7727-7730.

Mordes, D. A. and Cortez, D. (2008). Activation of ATR and related PIKKs. Cell Cycle 7, 2809-2812

Moyal, L., Lerenthal, Y., Gana-Weisz, M., Mass, G., So, S., Wang, S.-Y., Eppink B., Chung, Y. M., Shalev, G., Shema, E. et al. (2011). Requirement of ATM dependent monoubiquitylation of histone $\mathrm{H} 2 \mathrm{~B}$ for timely repair of DNA doublestrand breaks. Mol. Cell 41, 529-542.

Mu, J.-J., Wang, Y., Luo, H., Leng, M., Zhang, J., Yang, T., Besusso, D., Jung, S. Y. and Qin, J. (2007). A proteomic analysis of ataxia telangiectasia-mutated (ATM)/ATM-Rad3-related (ATR) substrates identifies the ubiquitin-proteasome system as a regulator for DNA damage checkpoints. J. Biol. Chem. 282 17330-17334.

Nam, E. A. and Cortez, D. (2011). ATR signalling: more than meeting at the fork. Biochem. J. 436, 527-536.

Negrini, S., Gorgoulis, V. G. and Halazonetis, T. D. (2010). Genomic instability an evolving hallmark of cancer. Nat. Rev. Mol. Cell Biol. 11, 220-228.

Nevanlinna, H. and Bartek, J. (2006). The CHEK2 gene and inherited breast cancer susceptibility. Oncogene 25, 5912-5919.

Nghiem, P., Park, P. K., Kim, Y.-s., Vaziri, C. and Schreiber, S. L. (2001). ATR inhibition selectively sensitizes G1 checkpoint-deficient cells to lethal premature chromatin condensation. Proc. Natl. Acad. Sci. USA 98, 9092-9097.

O'Driscoll, M., Ruiz-Perez, V. L., Woods, C. G., Jeggo, P. A. and Goodship, J. A (2003). A splicing mutation affecting expression of ataxia-telangiectasia and Rad3-related protein (ATR) results in Seckel syndrome. Nat. Genet. 33, 497-501.

Okuno, Y., Nakamura-Ishizu, A., Otsu, K., Suda, T. and Kubota, Y. (2012) Pathological neoangiogenesis depends on oxidative stress regulation by ATM. Nat. Med. 18, 1208-1216.

Olcina, M. M., Foskolou, I. P., Anbalagan, S., Senra, J. M., Pires, I. M., Jiang, Y., Ryan, A. J. and Hammond, E. M. (2013). Replication stress and chromatin context link ATM activation to a role in DNA replication. Mol. Cell 52, 758-766.

Paull, T. T. (2015). Mechanisms of ATM activation. Annu. Rev. Biochem. 84, 711-738.

Paulsen, R. D. and Cimprich, K. A. (2007). The ATR pathway: fine-tuning the fork. DNA Repair 6, 953-966.

Paulsen, R. D., Soni, D. V., Wollman, R., Hahn, A. T., Yee, M.-C., Guan, A. Hesley, J. A., Miller, S. C., Cromwell, E. F., Solow-Cordero, D. E. et al. (2009). A genome-wide siRNA screen reveals diverse cellular processes and pathways that mediate genome stability. Mol. Cell 35, 228-239.

Peng, C.-Y., Graves, P. R., Thoma, R. S., Wu, Z., Shaw, A. S. and PiwnicaWorms, H. (1997). Mitotic and G2 checkpoint control: regulation of 14-3-3 protein binding by phosphorylation of Cdc25C on serine-216. Science 277, 1501-1505.

Peng, A., Lewellyn, A. L., Schiemann, W. P. and Maller, J. L. (2010). Repo-man controls a protein phosphatase 1-dependent threshold for DNA damage checkpoint activation. Curr. Biol. 20, 387-396.

Perry, J. and Kleckner, N. (2003). The ATRs, ATMs, and TORs are giant HEAT repeat proteins. Cell 112, 151-155.

Petermann, E., Maya-Mendoza, A., Zachos, G., Gillespie, D. A. F., Jackson, D. A. and Caldecott, K. W. (2006). Chk1 requirement for high global rates of replication fork progression during normal vertebrate S phase. Mol. Cell. Biol. 26 3319-3326.

Petermann, E., Woodcock, M. and Helleday, T. (2010). Chk1 promotes replication fork progression by controlling replication initiation. Proc. Natl. Acad. Sci. USA 107, 16090-16095

Polo, S. E., Kaidi, A., Baskcomb, L., Galanty, Y. and Jackson, S. P. (2010). Regulation of DNA-damage responses and cell-cycle progression by the chromatin remodelling factor CHD4. EMBO J. 29, 3130-3139.

Pusapati, R. V., Rounbehler, R. J., Hong, S., Powers, J. T., Yan, M., Kiguchi, K., McArthur, M. J., Wong, P. K. and Johnson, D. G. (2006). ATM promotes apoptosis and suppresses tumorigenesis in response to Myc. Proc. Natl. Acad. Sci. USA 103, 1446-1451.

Reichenbach, J., Schubert, R., Schindler, D., Müller, K., Böhles, H. and Zielen, S. (2002). Elevated oxidative stress in patients with ataxia telangiectasia. Antioxid. Redox Signal. 4, 465-469.

Reiman, A., Srinivasan, V., Barone, G., Last, J. I., Wootton, L. L., Davies, E. G., Verhagen, M. M., Willemsen, M. A., Weemaes, C. M., Byrd, P. J. et al. (2011) Lymphoid tumours and breast cancer in ataxia telangiectasia; substantia protective effect of residual ATM kinase activity against childhood tumours. $\mathrm{Br} J$. Cancer 105, 586-591.

Renwick, A., Thompson, D., Seal, S., Kelly, P., Chagtai, T., Ahmed, M., North, B., Jayatilake, H., Barfoot, R., Spanova, K. et al. (2006). ATM mutations that cause ataxia-telangiectasia are breast cancer susceptibility alleles. Nat. Genet. 38 873-875

Roberts, N. J., Jiao, Y., Yu, J., Kopelovich, L., Petersen, G. M., Bondy, M. L., Gallinger, S., Schwartz, A. G., Syngal, S., Cote, M. L. et al. (2012). ATM mutations in patients with hereditary pancreatic cancer. Cancer Discov. 2, 41-46. Sanchez, Y., Wong, C., Thoma, R. S., Richman, R., Wu, Z., Piwnica-Worms, H. and Elledge, S. J. (1997). Conservation of the Chk1 checkpoint pathway in mammals: linkage of DNA damage to Cdk regulation through Cdc25. Science 277, 1497-1501.

Sarkaria, J. N., Tibbetts, R. S., Busby, E. C., Kennedy, A. P., Hill, D. E. and Abraham, R. T. (1998). Inhibition of phosphoinositide 3-kinase related kinases by the radiosensitizing agent wortmannin. Cancer Res. 58, 4375-4382.

Sarkaria, J. N., Busby, E. C., Tibbetts, R. S., Roos, P., Taya, Y., Karnitz, L. M. and Abraham, R. T. (1999). Inhibition of ATM and ATR kinase activities by the radiosensitizing agent, caffeine. Cancer Res. 59, 4375-4382. 
Sarmento, L. M., Póvoa, V., Nascimento, R., Real, G., Antunes, I., Martins, L. R. Moita, C., Alves, P. M., Abecasis, M., Moita, L. F. et al. (2015). CHK1 overexpression in T-cell acute lymphoblastic leukemia is essential for proliferation and survival by preventing excessive replication stress. Oncogene 34, 2978-2990.

Savitsky, K., Bar-Shira, A., Gilad, S., Rotman, G., Ziv, Y., Vanagaite, L., Tagle, D. A., Smith, S., Uziel, T., Sfez, S. et al. (1995). A single ataxia telangiectasia gene with a product similar to PI-3 kinase. Science 268, 1749-1753.

Segurado, M. and Diffley, J. F. X. (2008). Separate roles for the DNA damage checkpoint protein kinases in stabilizing DNA replication forks. Genes Dev. 22 , 1816-1827.

Seshagiri, S., Stawiski, E. W., Durinck, S., Modrusan, Z., Storm, E. E., Conboy, C. B., Chaudhuri, S., Guan, Y., Janakiraman, V., Jaiswal, B. S. et al. (2012) Recurrent R-spondin fusions in colon cancer. Nature 488, 660-664.

Shechter, D., Costanzo, V. and Gautier, J. (2004). ATR and ATM regulate the timing of DNA replication origin firing. Nat. Cell Biol. 6, 648-655.

Shiloh, Y. and Ziv, Y. (2013). The ATM protein kinase: regulating the cellular response to genotoxic stress, and more. Nat. Rev. Mol. Cell Biol. 14, 197-210.

Shreeram, S., Demidov, O. N., Hee, W. K., Yamaguchi, H., Onishi, N., Kek, C., Timofeev, O. N., Dudgeon, C., Fornace, A. J., Anderson, C. W. et al. (2006) Wip1 phosphatase modulates ATM-dependent signaling pathways. Mol. Cell 23 757-764.

So, S., Davis, A. J. and Chen, D. J. (2009). Autophosphorylation at serine 1981 stabilizes ATM at DNA damage sites. J. Cell Biol. 187, 977-990.

Spring, K., Ahangari, F., Scott, S. P., Waring, P., Purdie, D. M., Chen, P. C. Hourigan, K., Ramsay, J., McKinnon, P. J., Swift, M. et al. (2002). Mice heterozygous for mutation in Atm, the gene involved in ataxia-telangiectasia, have heightened susceptibility to cancer. Nat. Genet. 32, 185-190.

Squatrito, M., Brennan, C. W., Helmy, K., Huse, J. T., Petrini, J. H. and Holland, E. C. (2010). Loss of ATM/Chk2/p53 pathway components accelerates tumo development and contributes to radiation resistance in gliomas. Cancer Cell 18, 619-629.

St. Onge, R. P., Besley, B. D. A., Pelley, J. L. and Davey, S. (2003). A role for the phosphorylation of hRad9 in checkpoint signaling. J. Biol. Chem. 278 26620-26628.

Sun, Y., Jiang, X., Chen, S., Fernandes, N. and Price, B. D. (2005). A role for the Tip60 histone acetyltransferase in the acetylation and activation of ATM. Proc. Natl. Acad. Sci. USA 102, 13182-13187.

Sun, Y., Xu, Y., Roy, K. and Price, B. D. (2007). DNA damage-induced acetylation of lysine 3016 of ATM activates ATM kinase activity. Mol. Cell. Biol. 27, 8502-8509.

Tanaka, A., Weinel, S., Nagy, N., O’Driscoll, M., Lai-Cheong, J. E., KulpShorten, C. L., Knable, A., Carpenter, G., Fisher, S. A., Hiragun, M. et al. (2012). Germline mutation in ATR in autosomal- dominant oropharyngeal cance syndrome. Am. J. Hum. Genet. 90, 511-517.

Tho, L. M., Libertini, S., Rampling, R., Sansom, O. and Gillespie, D. A. (2012). Chk1 is essential for chemical carcinogen-induced mouse skin tumorigenesis. Oncogene 31, 1366-1375.

Toledo, L. I., Murga, M., Gutierrez-Martinez, P., Soria, R. and FernandezCapetillo, O. (2008). ATR signaling can drive cells into senescence in the absence of DNA breaks. Genes Dev. 22, 297-302.

Toledo, L. I., Murga, M., Zur, R., Soria, R., Rodriguez, A., Martinez, S., Oyarzabal, J., Pastor, J., Bischoff, J. R. and Fernandez-Capetillo, O. (2011). A cell-based screen identifies ATR inhibitors with synthetic lethal properties for cancer-associated mutations. Nat. Struct. Mol. Biol. 18, 721-727.

Toledo, L. I., Altmeyer, M., Rask, M.-B., Lukas, C., Larsen, D. H., Povlsen, L. K., Bekker-Jensen, S., Mailand, N., Bartek, J. and Lukas, J. (2013). ATR prohibits replication catastrophe by preventing global exhaustion of RPA. Cell 155 1088-1103

Tresini, M., Warmerdam, D. O., Kolovos, P., Snijder, L., Vrouwe, M. G., Demmers, J. A., van IJcken, W. F. J., Grosveld, F. G., Medema, R. H., Hoeijmakers, J. H. J. et al. (2015). The core spliceosome as target and effector of non-canonical ATM signalling. Nature 523, 53-58.

Turenne, G. A., Paul, P., Laflair, L. and Price, B. D. (2001). Activation of p53 transcriptional activity requires ATM's kinase domain and multiple $\mathrm{N}$-terminal serine residues of p53. Oncogene 20,5100-5110.

Unsal-Kacmaz, K. and Sancar, A. (2004). Quaternary structure of ATR and effects of ATRIP and replication protein A on its DNA binding and kinase activities. Mol. Cell. Biol. 24, 1292-1300.

Vadnais, C., Davoudi, S., Afshin, M., Harada, R., Dudley, R., Clermont, P.-L., Drobetsky, E. and Nepveu, A. (2012). CUX1 transcription factor is required for optimal ATM/ATR-mediated responses to DNA damage. Nucleic Acids Res. 40 , 4483-4495
Vahteristo, P., Bartkova, J., Eerola, H., Syrjäkoski, K., Ojala, S., Kilpivaara, O., Tamminen, A., Kononen, J., Aittomäki, K., Heikkilä, P. et al. (2002). A CHEK2 genetic variant contributing to a substantial fraction of familial breast cancer. Am. J. Hum. Genet. 71, 432-438.

Valentin-Vega, Y. A., Maclean, K. H., Tait-Mulder, J., Milasta, S., Steeves, M., Dorsey, F. C., Cleveland, J. L., Green, D. R. and Kastan, M. B. (2012). Mitochondrial dysfunction in ataxia-telangiectasia. Blood 119, 1490-1500.

van Gent, D. C., Hoeijmakers, J. H. J. and Kanaar, R. (2001). Chromosomal stability and the DNA double-stranded break connection. Nat. Rev. Genet. 2 196-206

Verlinden, L., Vanden Bempt, I., Eelen, G., Drijkoningen, M., Verlinden, I. Marchal, K., De Wolf-Peeters, C., Christiaens, M.-R., Michiels, L., Bouillon, R. et al. (2007). The E2F-regulated gene Chk1 is highly expressed in triple-negative estrogen receptor/progesterone receptor/HER-2 breast carcinomas. Cance Res. 67, 6574-6581.

Wang, X., Zou, L., Lu, T., Bao, S., Hurov, K. E., Hittelman, W. N., Elledge, S. J. and Li, L. (2006). Rad17 phosphorylation is required for claspin recruitment and Chk1 activation in response to replication stress. Mol. Cell 23, 331-341.

Weber, A. M., Soreni, N. and Noseworthy, M. D. (2014). A preliminary study on the effects of acute ethanol ingestion on default mode network and temporal fractal properties of the brain. MAGMA 27, 291-301.

Weiss, R. S., Enoch, T. and Leder, P. (2000). Inactivation of mouse Hus1 results in genomic instability and impaired responses to genotoxic stress. Genes Dev. 14, 1886-1898.

Wu, Z.-H., Shi, Y., Tibbetts, R. S. and Miyamoto, S. (2006). Molecular linkage between the kinase ATM and NF-kappaB signaling in response to genotoxic stimuli. Science 311, 1141-1146.

Xu, J., Li, Y., Wang, F., Wang, X., Cheng, B., Ye, F., Xie, X., Zhou, C. and Lu, W. (2013). Suppressed miR-424 expression via upregulation of target gene Chk1 contributes to the progression of cervical cancer. Oncogene 32, 976-987.

Yamada, M., Watanabe, K., Mistrik, M., Vesela, E., Protivankova, I., Mailand, N., Lee, M., Masai, H., Lukas, J. and Bartek, J. (2013). ATR-Chk1-APC/CCdh1dependent stabilization of Cdc7-ASK (Dbf4) kinase is required for DNA lesion bypass under replication stress. Genes Dev. 27, 2459-2472.

Yang, D. Q. and Kastan, M. B. (2000). Participation of ATM in insulin signalling through phosphorylation of elF-4E-binding protein 1. Nat. Cell Biol. 2, 893-898.

Yang, C., Tang, X., Guo, X., Niikura, Y., Kitagawa, K., Cui, K., Wong, S. T. C., Fu, L. and Xu, B. (2011). Aurora-B mediated ATM serine 1403 phosphorylation is required for mitotic ATM activation and the spindle checkpoint. Mol. Cell 44 597-608.

You, Z., Chahwan, C., Bailis, J., Hunter, T. and Russell, P. (2005). ATM activation and its recruitment to damaged DNA require binding to the $\mathrm{C}$ terminus of $\mathrm{Nbs} 1$. Mol. Cell. Biol. 25, 5363-5379.

Zhang, X., Wan, G., Berger, F. G., He, X. and Lu, X. (2011). The ATM kinase induces microRNA biogenesis in the DNA damage response. Mol. Cell. $\mathbf{4 1}$ 371-383.

Zhang, T., Penicud, K., Bruhn, C., Loizou, J. I., Kanu, N., Wang, Z.-Q. and Behrens, A. (2012). Competition between NBS1 and ATMIN controls ATM signaling pathway choice. Cell Rep. 2, 1498-1504.

Zhao, H. and Piwnica-Worms, H. (2001). ATR-mediated checkpoint pathways regulate phosphorylation and activation of human Chk1. Mol. Cell. Biol. 21, 4129-4139.

Zhao, H., Watkins, J. L. and Piwnica-Worms, H. (2002). Disruption of the checkpoint kinase $1 /$ cell division cycle $25 \mathrm{~A}$ pathway abrogates ionizing radiationinduced S and G2 checkpoints. Proc. Natl. Acad. Sci. USA 99, 14795-14800.

Zighelboim, I., Schmidt, A. P., Gao, F., Thaker, P. H., Powell, M. A., Rader, J. S Gibb, R. K., Mutch, D. G. and Goodfellow, P. J. (2009). ATR mutation in endometrioid endometrial cancer is associated with poor clinical outcomes. J. Clin. Oncol. 27, 3091-3096.

Zighelboim, I., Ali, S., Lankes, H. A., Backes, F., Moore, K., Mutch, D., Robison, K., Behbakht, K., Waggoner, S., Ghebre, R. G. et al. (2015). Assessing the prognostic role of ATR mutation in endometrioid endometrial cancer: An NRG Oncology/Gynecologic Oncology Group study. Gynecol. Oncol. 138, 614-619.

Ziv, Y., Bielopolski, D., Galanty, Y., Lukas, C., Taya, Y., Schultz, D. C., Lukas, J., Bekker-Jensen, S., Bartek, J. and Shiloh, Y. (2006). Chromatin relaxation in response to DNA double-strand breaks is modulated by a novel ATM- and KAP-1 dependent pathway. Nat. Cell Biol. 8, 870-876.

Zou, L. and Elledge, S. J. (2003). Sensing DNA damage through ATRIP recognition of RPA-ssDNA complexes. Science 300, 1542-1548.

Zou, L., Liu, D. and Elledge, S. J. (2003). Replication protein A-mediated recruitment and activation of Rad17 complexes. Proc. Natl. Acad. Sci. USA 100 13827-13832. 